\title{
Director reorientation in a cell with time-dependent anchoring due to adsorption/desorption of LC molecules
}

\author{
A.Romanenko, I.Pinkevich, V.Reshetnyak, I.Dozov", D.Stoenescu* \\ Physics Faculty, T.Shevchenko Kyiv National University, 6 Acad. \\ Glushkov Ave., 03022 Kyiv, Ukraine \\ *NEMOPTIC, Parc du Merantais, 1 rue Guynemer, \\ 78114 Magny les Hameaux, France
}

\begin{abstract}
Influence of adsorption/desorption process of nematic molecules at the nematic cell substrate on the nematic crystal director evolution in time that is due to external magnetic field has been considered. It is shown that boundary conditions at the cell surface evolve in accordance with the distribution of nematic molecular orientation in the cell bulk. During the time evolution, the orientation distribution function of molecules adsorbed at the cell substrate can exhibit two maxima. By switching off the magnetic field at the suitable moment, it is possible obtain a bistable nematic system.
\end{abstract}

Рассмотрено влияние процесса адсорбции/десорбции молекул нематика на одной из поверхностей нематической ячейки на временную эволюцию директора нематического жидкого кристалла, обусловленную внешним магнитным полем. Показано, что граничные условия на поверхности ячейки согласуются с объемным распределением ориентации молекул нематика. В течение времени эволюции функция распределения ориентации молекул адсорбированных на поверхности ячейки, может иметь два максимума. Это позволяет получить бистабильную нематическую систему, если в соответствующий момент времени выключить магнитное поле.

The possibility to control precisely the anchoring energy of liquid crystals (LC) on photo-aligning polymers makes them the most promising materials for weak and memory-free anchoring. The problem which hampers their application is the strong alignment memory effect. This effect is caused by anisotropic adsorption of LC molecules at the aligning surface and is observed for most aligning materials [1]. The adsorbed layer behaves as a new, anisotropic substrate imposing a strong monostable anchoring [2]. The purpose of this work is to investigate the time evolution of the director orientation in the cell subjected to an external magnetic (or electric) field in the case of time-dependent boundary conditions determined by the adsorption/desorption processes of LC molecules at the cell substrate.
Let a nematic cell be considered bound by the planes $z=0$ and $z=l$. We suppose the director anchoring at the plane $z=0$ to be planar and infinitely strong, with the director easy axis along the axis $O x$. The director anchoring at the plane $z=l$ is planar as well but both the director easy axis and anchoring energy depend on the adsorption/desorption processes of LC molecules at this plane. At $t=0$, the magnetic field $\mathbf{H}=H \mathbf{e}_{y}$ is switched on $\left(\mathbf{e}_{y}\right.$ is a unit vector along the axis $O y$ ). Then the director orientation in the cell bulk changes that influences the adsorption/desorption processes of LC molecules at the plane $z=l$. As a result, the boundary conditions on the plane $z=l$ change as well and influence (in their turn) the director orientation in the cell bulk. We suppose the director orientation in the cell bulk to follow adiabatically the boundary conditions. 
Denoting the director angle with the axis $O x$ by $\varphi$, we can describe the director spatial distribution in the form

$$
\mathbf{n}(z)=\mathbf{e}_{\mathbf{x}} \cos \varphi(z)+\mathbf{e}_{\mathbf{y}} \sin \varphi(z) .
$$

Using this notation, we can write the expression for nematic cell free energy in the magnetic field

$=\frac{1}{2} \int_{0}^{l} d z\left[K\left(\frac{\partial \varphi(z, t)}{\partial z}\right)^{2}-\chi_{a} H^{2} \sin ^{2} \varphi(z, t)\right]-W_{S}(t)$

(here we use one constant approximation) and taking the variation of this functional, we obtain the equation

$$
\varphi^{\prime \prime}(z)+\frac{\chi_{a} H^{2}}{K} \sin \varphi(z) \cos \varphi(z)=0, \frac{1}{\xi^{2}}=\frac{\chi_{a} H^{2}}{K}
$$

with boundary conditions

$$
\varphi(0)=0, \quad\left[K \varphi^{\prime}(z)-\frac{\partial W_{S}[\varphi(z)]}{\partial \varphi(z)}\right]_{z=l}=\mathbf{0} .
$$

Here, $K$ is the Frank's elastic constant; $\chi_{a}$, the magnetic susceptibility anisotropy; $W_{S}(\varphi)$, the director anchoring energy at the plane $z=l$ (its actual form depends on the adsorption/desorption processes and has to be defined below).

The solution of Eq.(2) can be written as

$$
\sin \varphi(z)=k \operatorname{sn}(z / \xi, k),
$$

where $\operatorname{sn}(\alpha z, k)$ is an elliptic Jacobi sine function, the parameter $k$ can be determined from the second boundary condition (3) which takes the form

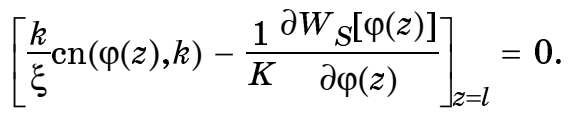

Thus, the director distribution in a nematic cell is described by expressions (4) and (5). To calculate it, we have to know the true form of the director anchoring energy $W_{S}[\varphi]$.

We suppose the interaction of LC molecules with molecules of the substrate material to be isotropic and the only interaction with LC molecules adsorbed on the substrate to contribute to the anchoring energy $W_{S}[\varphi]$. Similarly to Mayer-Saupe theory [4], we can introduce the orientation distribution function for LC molecules near the cell surface

$$
f_{\text {vol }}\left(\Omega_{1}, t\right)=\frac{1}{N_{\text {vol }}} \exp \left(\beta P_{2}\left(\mathbf{l}_{\mathbf{1}} \cdot \mathbf{n}\right)\right), \quad \beta=\frac{a S}{k_{B} T},
$$

where

$$
\mathbf{l}_{\mathbf{1}}=\left(\sin \theta_{1} \cos \varphi_{1}, \sin \theta_{1} \sin \varphi_{1}, \cos \theta_{1}\right)
$$

is a unit vector along the long molecule axis; $P_{2}$, the Legendre polynomial; $S$, the order parameter; $a$, a constant that describes the strength of molecular anisotropic interaction in the mean field approximation; $\Omega_{1}=\left\{\theta_{1}, \varphi_{1}\right\}$, and $N_{v o l}$, a normalization constant. Here the director depends on the time due to adsorption/desorption processes at the plane $z=l$.

Let us denote the orientation distribution function of the molecules adsorbed at the cell substrate as $f_{\text {surf }}\left(\Omega_{2}, t\right)$. It is evident that

$$
f_{\text {surf }}\left(\Omega_{2}, t\right)=f_{S}\left(\varphi_{2}, t\right) \delta\left(\cos \theta_{2}\right),
$$

where the last multiplier displays the fact that all the molecules lie on the substrate.

Further, we adopt that interaction between LC molecules and molecules in the bulk near the surface depends on their long axes orientation in the form $\left(\mathbf{e}_{1} \cdot \mathbf{e}_{2}\right)^{2}$ where $\mathbf{e}_{1,2}$ are the unit vectors along the long molecular axis. Hence, we assume the following expression for $W_{S}[\varphi]$ :

$$
\begin{gathered}
W_{S}[\varphi]=W_{0} \iint d \Omega_{1} d \Omega_{2}\left(\mathbf{l}_{\mathbf{1}} \cdot \mathbf{l}_{2}\right) f_{v o l}\left(\Omega_{1}, t\right) f_{\text {surf }}\left(\Omega_{2}, t\right), \\
W_{0}<0,
\end{gathered}
$$

where $\mathbf{l}_{2}$ is a unit vector along the long axis of the adsorbed molecule.

Substituting the expressions (6) and (8) into (9), we obtain the following expression for the director anchoring energy

$$
\begin{gathered}
W_{S}[\varphi]= \\
=\frac{1}{2}\left[I_{S}(t) \bar{I}_{V}(t)+\bar{C}_{2 V}(t) \sqrt{C_{2 S}^{2}(t)+S_{2 S}^{2}(t)} \cos 2\left(\varphi-\varphi_{S}(t)\right)\right.
\end{gathered}
$$

where the angle $\varphi_{S}(t)$ is defined as

$$
\begin{aligned}
& \sin 2 \varphi_{S}(t)=\frac{S_{2 S}(t)}{\sqrt{C_{2 S}^{2}(t)+S_{2 S}^{2}(t)}}, \\
& \cos 2 \varphi_{S}(t)=\frac{C_{2 S}(t)}{\sqrt{C_{2 S}^{2}(t)+S_{2 S}^{2}(t)}}
\end{aligned}
$$

and 


$$
\begin{gathered}
I_{S}(t)=\int_{-\pi / 2}^{\pi / 2} f_{S}(\alpha, t) d \alpha, \bar{I}_{V}(t)=\int_{-\pi / 2}^{\pi / 2} f_{V}(\alpha, t) d \alpha \\
\bar{C}_{2 V}(t)=\int_{-\pi / 2}^{\pi / 2} \bar{f}_{V}(\alpha, t) \cos 2 \alpha d \alpha \\
\left.\bar{f}_{V}\left(\varphi_{1}, t\right)=\int_{v o l}^{\pi} f_{v}, t\right) \sin ^{3} \alpha d \alpha \\
C_{2 S}(t)=\int_{-\pi / 2}^{\pi / 2} f_{S}(\alpha, t) \cos 2 \alpha d \alpha \\
-\pi / 2 \\
S_{2 S}(t)=\int_{-\pi / 2} f_{S}(\alpha, t) \sin 2 \alpha d \alpha .
\end{gathered}
$$

The expression (10) is similar to Rapini potential [3] but the anchoring strength and the easy axis orientation are now time dependent.

Since the distribution function $f_{v o l}\left(\Omega_{1}, t\right)$ is supposed to be known (see Eq.(6)), we can calculate $\bar{I}_{V}$ and $\bar{C}_{2 V}$. But to find $I_{S}, C_{2 S}$, and $S_{2 S}$, we need to know the distribution function $f_{S}(\varphi, t)$ for molecules at the cell substrate.

The following kinetic equation can be written:

$$
\frac{\partial f_{S}\left(\varphi_{1}, t\right)}{\partial t}=A_{+} f_{V}\left(\varphi_{1}, t\right)-A_{-} f_{S}\left(\varphi_{1}, t\right)
$$

where $f_{V}\left(\varphi_{1}, t\right)=\int_{0}^{\pi} f_{v o l}\left(\Omega_{1}, t\right) \sin \theta_{1} d \theta_{1}$ is a 2 -dimensional projection of the function (6); $A_{ \pm}$ are the coefficients describing the adsorption/desorption rates. As the initial condition for the equation (13), we choose its stationary form:

$$
f_{S}\left(\varphi_{1}, 0\right)=\frac{A_{+}}{A_{-}} f_{V}\left(\varphi_{1}, 0\right) .
$$

If the distributions $f_{S}(\varphi, t)$ and $f_{V}(\varphi, t)$ are normalized, the kinetic equation must be changed in order to meet the requirement (14). It has been found that it is sufficient to put $A_{+}=A_{-}$in this case. To find $C_{2 S}$ and $S_{2 S}$, we can multiply both sides of the equation (13) first by $\sin 2 \varphi_{1}$ and second by $\cos 2 \varphi_{1}$. Then, upon integrating the obtained expressions over $\varphi_{1}$ and $t$ we get:

$$
\begin{gathered}
S_{2 S}(t)= \\
=S_{2 S}(0) e^{-A_{-} t}+A_{+} C_{2 V} \int_{0}^{t} e^{-A_{+}(t-\tau)} \sin 2 \varphi(t) d \tau, \\
C_{2 S}(t)= \\
=C_{2 S}(0) e^{-A_{-} t}+A_{+} C_{2 V} \int_{0}^{t} e^{-A_{+}(t-\tau)} \cos 2 \varphi(t) d \tau,
\end{gathered}
$$

where

$$
C_{2 V}=\frac{2 \pi e^{-\beta / 2}}{N_{v o l} 3 \beta / 2}\left(e^{3 / 2}-1\right)-1
$$

Similarly, integrating the equation (13) over $\varphi_{1}$ and $t$ we obtain

$$
I_{S}(t)=A_{+} / A_{-}
$$

(is constant). Substituting the expressions (12), (15), and (17) into the formula (10), we obtain following form of the boundary condition (5):

$$
\begin{gathered}
{[\alpha k \operatorname{cn}(z / \xi, k))+} \\
+W_{0}\left[S_{2 S}(0) \cos 2 \varphi-C_{2 S}(0) \sin 2 \varphi\right] e^{-A_{-} t}- \\
\left.-W_{0} C_{2 V}(t) \bar{C}_{2 V}(t) \int_{0}^{t} e^{-A_{-}(t-\tau)} \sin 2(\varphi-\varphi(\tau)) d \tau\right]_{z=l}=0,
\end{gathered}
$$

where $\bar{C}_{2 V}(t)$ and $C_{2 v}(t)$ are determined by the formulas (12), (16) and $C_{2 S}(0)$ and $S_{2 S}(0)$ can be easily calculated using the condition (14). Finally, it should be noted here that both the angle $\varphi$ and parameter $k$ in equations (4), (18) depends now on the time $t$.

The equations (4), (18) as well as the equation (13) were solved numerically at the next values of parameters: $W_{0} \xi / K=10^{-2}, l / \xi=2$ and $A_{+}=A_{-}=1 \mathrm{~s}^{-1}$. Some calculated results are presented in Fig. 1, 2, and 3.

In Fig. 1, the time evolution of orientation distribution function $f_{S}(\varphi, t)$ of molecules adsorbed at the cell substrate is shown. It is seen that after the magnetic field is switched on, the distribution function $f_{S}(\varphi, t)$ changes forced by the adsorption of LC molecules at the cell substrate from the cell bulk with orientation distribution described near the cell plane $z=l$ by the function $f_{V}(\varphi(z=l), t)$. It is interesting to note that during the time evolution, the 

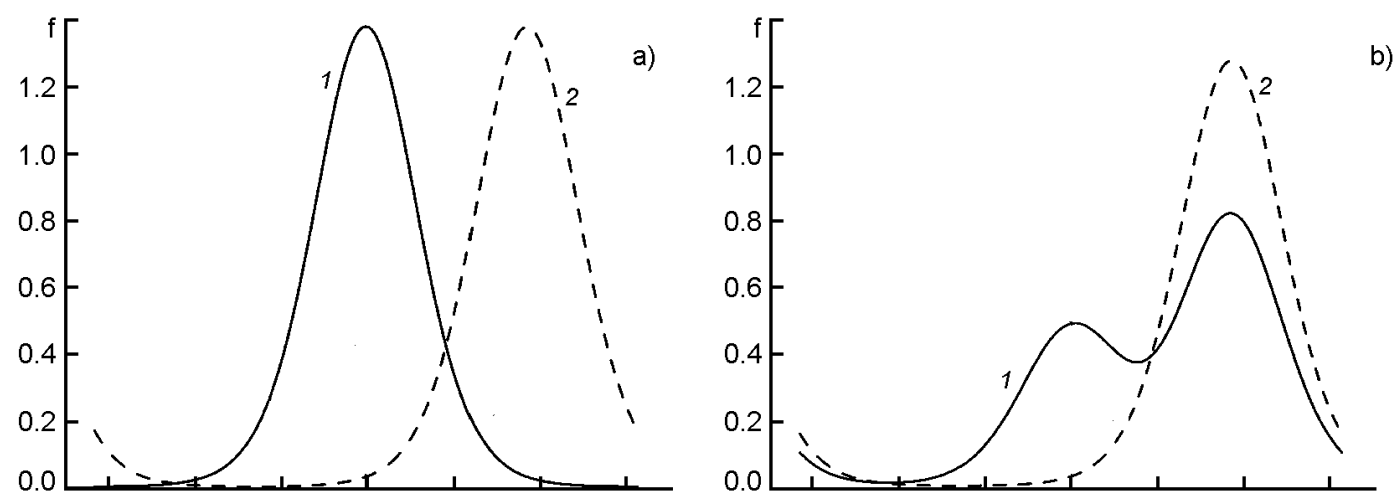

b)
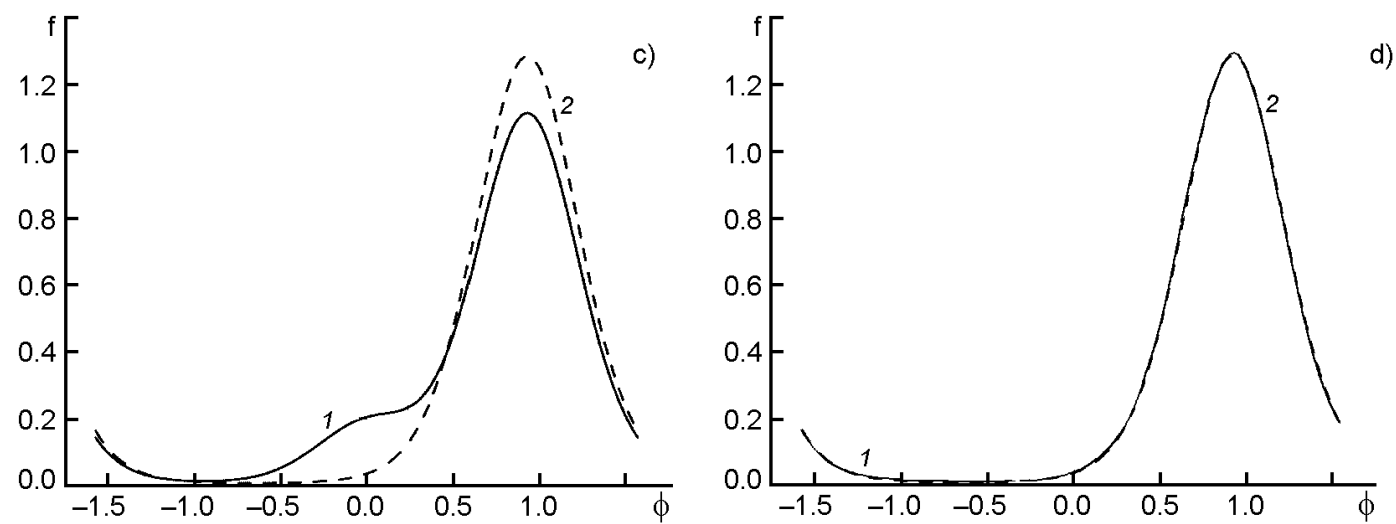

d)

Fig. 1. Distribution functions $f_{s}(\varphi, t)(1)$ and $f_{v}(\varphi, t)(2)$ for different time moments: a) $\tau=0$, b) $\tau=1$, c) $\tau=2$, d) $\tau=10 . \tau=A_{-} t$.

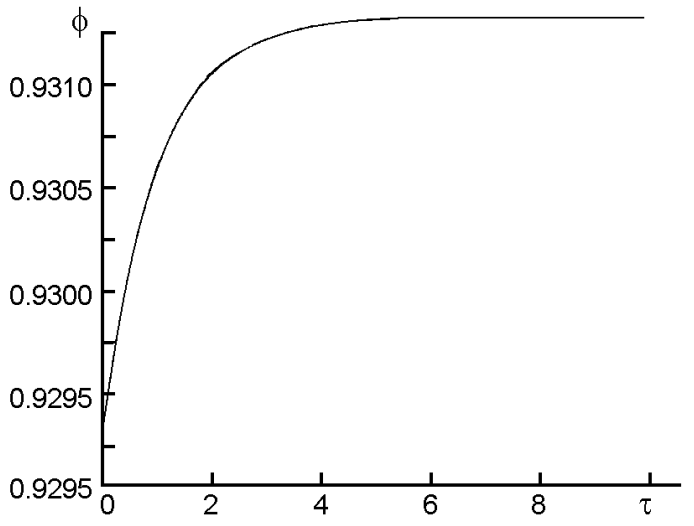

Fig. 2. Time evolution of the director angle $\varphi(z, t)$ for $z=l . \tau=A_{-} t$.

function $f_{S}(\varphi, t)$ can exhibit two maxima. It means that if at the proper moment the magnetic field is switched off, one can obtain a bistable nematic system.

The time evolution of the director orientation near the cell plane $z=l$ due to the adsorption/desorption processes of LC molecules is shown in Fig. 2. Fig. 3 presents the change in time of the angle $\varphi_{S}$, which describes "the easy axis" direction in the formula (10) similar to the Rapini-Papoular

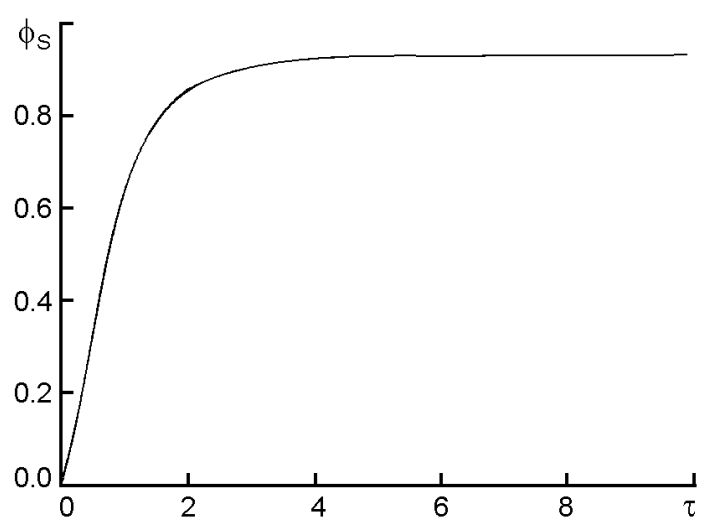

Fig. 3. Time evolution of "the easy axis" direction angle $\varphi_{S} \cdot \tau=A_{-} t$.

one. It is found that the angle $\varphi_{S}$ runs to the same limit as $\varphi(l, t)$ that is different from the case when $t \rightarrow \infty$ adsorption/desorption process is absent.

Finally, we note that the adsorption/desorption processes of LC molecules can influence essentially the boundary conditions at the cell surface. This effect can be used to obtain a bistable nematic system.

Acknowledgements. This work was supported by INTAS grant No.01-170.

Functional materials, 12, 1, 2005 


\section{References}

1. J.Cheng, G.D.Boyd, Appl.Phys. Lett., 35, 444 (1979).

2. D.Stoenescu, Ph.D.Thesis, Univ. P.Sabatier, Toulouse (1998).
3. A.Rapini, M.Papoular, J.Phys. Colloq., 30, 54 (1969).

4. P.G.de Gennes, The Physics of Liquid Crystals, Clarendon Press, Oxford (1974).

\section{Переорієнтація директора у комірці із залежним від часу зчепленням внаслідок адсорбції/десорбції молекул рідкого кристалу}

\section{А.Романенко, І.Пінкевич, В.Решетняк, І.Дозов, Д.Стоєнеску}

Розглянуто вплив процесу адсорбції/десорбції молекул нематика на одній із поверхонь нематичної комірки на часову еволюцію директора нематичного рідкого кристалу, зумовлену зовнішнім магнітним полем. Показано, що граничні умови на поверхні комірки узгоджуються з об’ємним розподілом орієнтації молекул нематика. Протягом часу еволюції функція розподілу орієнтації молекул адсорбованих на поверхні комірки може мати два максимуми. Це дозволяє отримати бістабільну нематичну систему, якщо у відповідний момент часу вимкнути магнітне поле. 